\title{
Gas embolism and hyperbaric oxygen therapy: a case series
}

\author{
Jeffrey CW Chau ${ }^{1}$ *, MB, BS, MRCS(Ed), Joe KS Leung', MB, ChB, FRCS, WW Yan², FRCP, FHKCP \\ ${ }^{1}$ Department of Accident and Emergency, Pamela Youde Nethersole Eastern Hospital, Hong Kong \\ ${ }^{2}$ Intensive Care Unit, Pamela Youde Nethersole Eastern Hospital, Hong Kong \\ * Corresponding author: drjhealthcare@gmail.com
}

Hong Kong Med J 2021;27:362-5

https://doi.org/10.12809/hkmj208928

\section{Case reports}

\section{Patient 1}

A 79-year-old man presented with left-sided weakness, drowsiness and dysphasia following left atrial appendage occlusion implantation in a cardiac intensive care unit. A sudden drop in systolic blood pressure to $40 \mathrm{mmHg}$ was noted. Echocardiogram and angiogram revealed no obvious coronary artery disease. Computed tomography (CT) of the brain showed no major vessel occlusion or gas pocket. A new CT of the brain showed more established infarct and oedema. Four sessions of hyperbaric oxygen therapy (HBOT) were conducted in accordance with United States Navy Treatment Tables (USNTT) ${ }^{1}$ : two USNTT6 and two USNTT5.

\section{Patient 2}

A 40-year-old woman was admitted to a surgical unit for suspected acute appendicitis. Urgent CT of the abdomen with contrast was performed, but approximately $60 \mathrm{~mL}$ of air was injected intravenously during the procedure and gas was evident in the right ventricle. Luckily, she was asymptomatic as the gas emboli had entered only the venous system and remained in the heart. One session of HBOT was conducted with USNTT6.

\section{Patient 3}

A 57-year-old woman underwent fine needle aspiration cytology under CT guidance for lung mass. The patient developed sudden onset bilateral anopia and left upper limb weakness during the procedure. Computed tomography brain and thorax identified a small gas embolism in the pulmonary vein with pulmonary haemorrhage. No obvious gas bubble was noted in the brain. A total of four sessions of HBOT were conducted with two USNTT6 and two USNTT5.

\section{Patient 4}

An 84-year-old man underwent CT-guided lung biopsy for right lung mass but experienced an acute deterioration in Glasgow Coma Scale (GCS) score.
Urgent CT of the brain showed multiple acute gas emboli and confirmed the diagnosis of cerebral arterial gas embolism (AGE). On arrival at the HBOT centre, he had GCS of 13/15 and right limb weakness with power of $1 / 5$ and $3 / 5$, respectively. Two sessions of HBOT were conducted with USNTT6.

\section{Patient 5}

A 66-year-old man with biliary pancreatitis underwent urgent endoscopic retrograde cholangiopancreatography. After the procedure he developed left-sided weakness with limb power of $0 / 5$ after 5 minutes. Urgent $C T$ of the brain revealed branching gas densities at the sulcal space of his right frontal and parietal lobes (Fig 1). Two sessions of HBOT with USNTT6 were conducted and the patient's symptoms considerably improved.

\section{Patient 6}

A 72-year-old man underwent CT-guided fine needle aspiration cytology for a lung lesion. The patient developed transient hypotension on needle removal and CT of the thorax revealed gas embolism in his left ventricle with no pneumothorax (Fig 2). The patient remained asymptomatic with no neurological deficit. Gas embolism had been introduced through the pulmonary circulation but remained in the heart, avoiding the complication of cerebral arterial occlusion. One session of HBOT was conducted with USNTT6.

\section{Discussion}

Gas embolism is a serious and life-threatening condition. It is usually iatrogenic and should be treated promptly to prevent serious complications such as cerebral AGE. It presents with sudden deterioration in neurological and haemodynamic status following risky medical procedures, most notably lung biopsy and cardiac interventions. This case report revealed six patients with gas embolism: five with AGE and one with venous gas embolism. Four patients with AGE manifested as cerebral AGE with neurological deficits such as limb weakness and anopia (Table). 

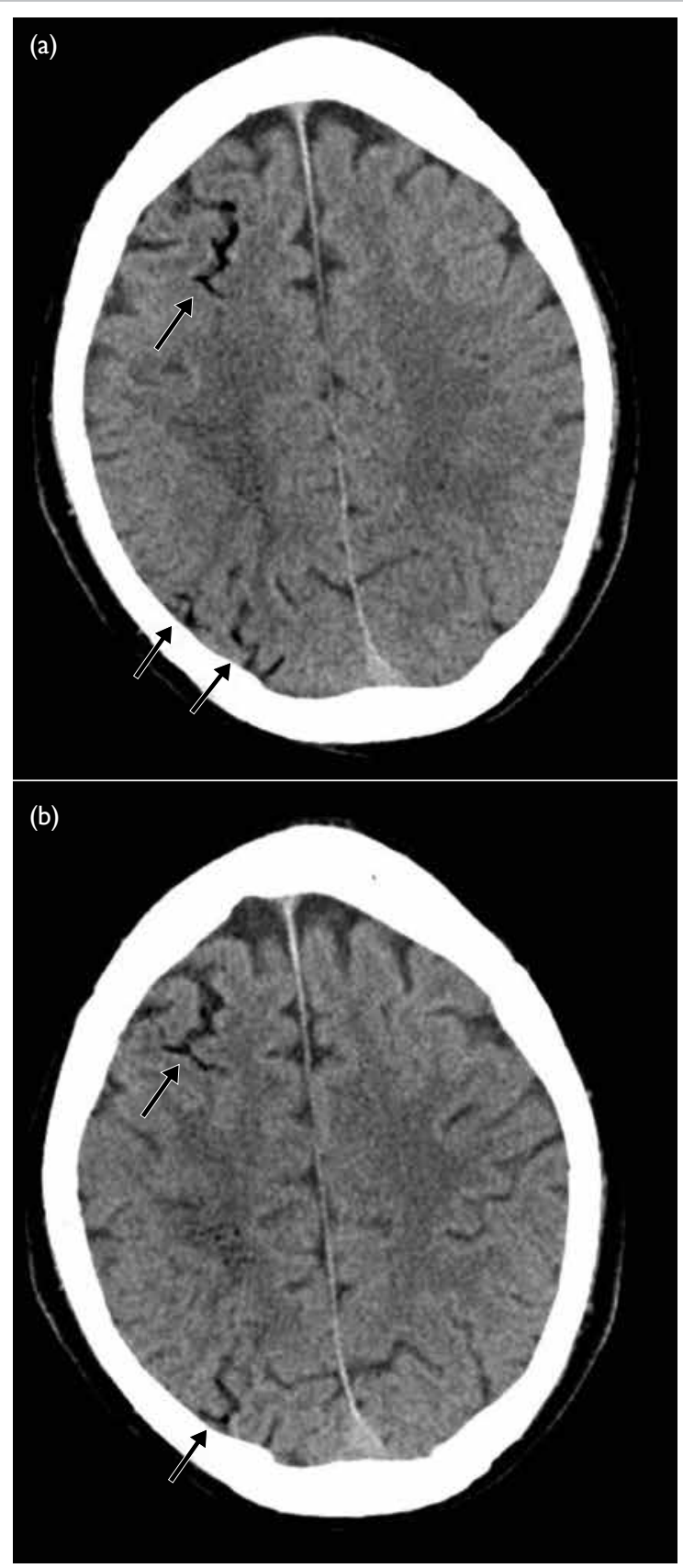

FIG I. (a, b) A 66-year-old man with biliary pancreatitis developed left-sided weakness 5 minutes after urgent endoscopic retrograde cholangiopancreatography. Computed tomography of the brain revealed branching gas density in the right frontal and parietal lobes (arrows)

\section{Rationale for using hyperbaric oxygen therapy}

As soon as AGE is suspected, the patient should start receiving $100 \%$ high-flow oxygen and be placed in the right lateral decubitus position. The definitive treatment for AGE is HBOT with $100 \%$ oxygen, although no randomised controlled trials
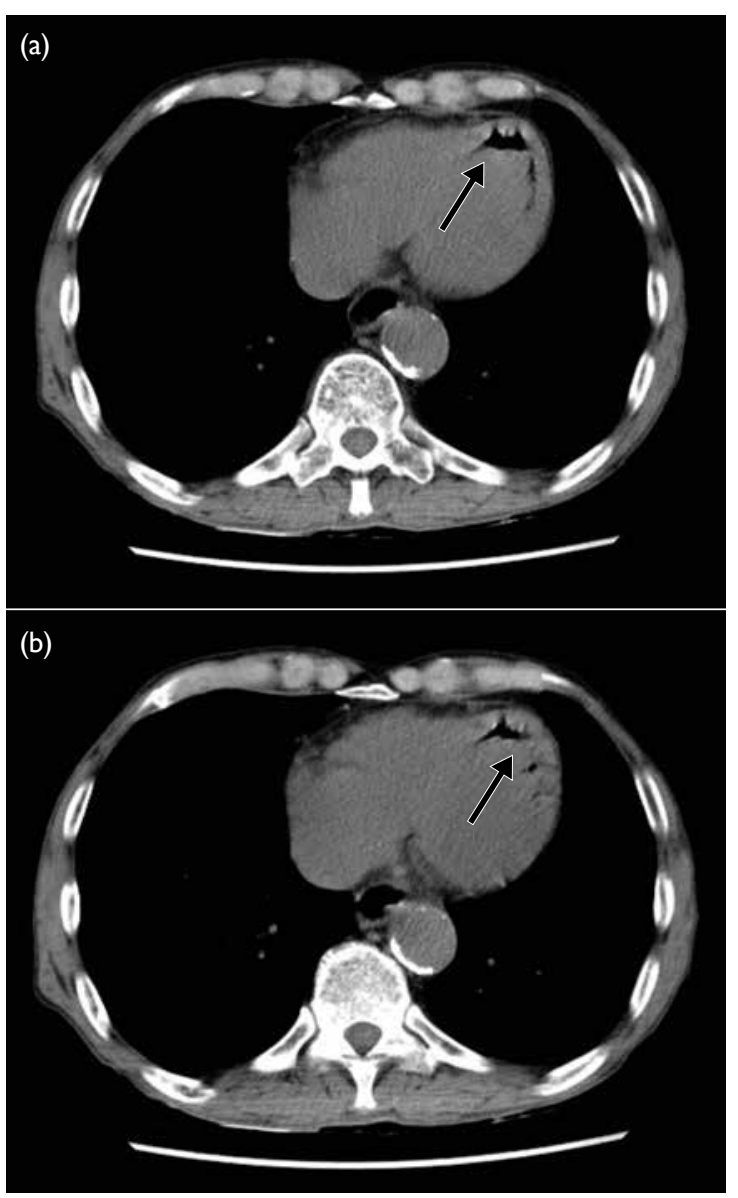

FIG 2. (a, b) A 72-year-old man developed transient hypotension on needle removal after computed tomography-guided fine needle aspiration cytology for a lung lesion. Computed tomography of the thorax revealed gas density (arrows) evident in the left ventricle with no pneumothorax

have been conducted to confirm its efficacy in this disease. Hyperbaric oxygen therapy "crushes" the bubbles with pressure, accelerates gas diffusion and bubble resolution with oxygen, oxygenates ischaemic tissue, reduces cerebral oedema, and decreases neutrophil adhesion to the endothelium. ${ }^{1,2}$ A retrospective study in France showed that the initial neurological symptoms were impaired consciousness (70\%), focal motor deficits $(60 \%)$, seizures (11\%), visual disturbance (10\%), dysarthria/ aphasia (5\%) and vertigo (5\%). In all, $26 \%$ of patients were haemodynamically unstable and subject to hypotension, circulatory collapse, and cardiac arrest. Respiratory disturbances such as dyspnoea, cough or chest pain were present in $23 \%$ of patients. ${ }^{3}$

In a study of 45 patients with AGE, good neurological outcome was achieved in $27(60 \%)$ of them. ${ }^{4}$ Time to receipt of HBOT was the only statistically significant factor predictive of a good 
TABLE. Patients treated with HBOT for cerebral arterial gas embolism

\begin{tabular}{|c|c|c|c|c|c|}
\hline $\begin{array}{l}\text { Patient } \\
\text { (age/sex) }\end{array}$ & $\begin{array}{l}\text { Procedure causing } \\
\text { gas embolism }\end{array}$ & Symptom & $\begin{array}{l}\text { Onset to HBOT } \\
\text { time (hr:min) }\end{array}$ & $\begin{array}{c}\text { No. of HBOT } \\
\text { treatments } \\
\text { (USNTT6:USNTT5) }\end{array}$ & Outcome \\
\hline $1(79 / M)$ & Cardiac intervention & $\begin{array}{l}\text { Shock; decreased } \\
\text { consciousness; convulsion; } \\
\text { left hemiplegia }\end{array}$ & $5: 17$ & $4(2: 2)$ & $\begin{array}{l}\text { Convulsion required anticonvulsant to } \\
\text { control, poor general condition required } \\
\text { bedrest and daily care. Subsequent } \\
\text { peer review concluded that the } \\
\text { patient's condition was compatible with } \\
\text { ischaemic stroke related to gas, clot } \\
\text { and hypotension during the crisis }\end{array}$ \\
\hline $2(40 / F)$ & $\begin{array}{l}\text { Injection of CT } \\
\text { contrast agent }\end{array}$ & Asymptomatic & $6: 44$ & $1(1: 0)$ & $\begin{array}{l}\text { Remained asymptomatic with bubbles } \\
\text { resolved on CT imaging }\end{array}$ \\
\hline $3(57 / F)$ & Lung biopsy & $\begin{array}{l}\text { Convulsion; left hemiplegia; } \\
\text { bilateral anopia }\end{array}$ & $4: 12$ & $4(2: 2)$ & $\begin{array}{l}\text { Limb power recovered, bilateral visual } \\
\text { acuity partially improved; bubbles } \\
\text { resolved on CT imaging }\end{array}$ \\
\hline $4(84 / M)$ & Lung biopsy & $\begin{array}{l}\text { Decreased consciousness; } \\
\text { right hemiplegia }\end{array}$ & $3: 39$ & $2(2: 0)$ & $\begin{array}{l}\text { Fully recovered and bubbles resolved } \\
\text { on } \mathrm{CT} \text { imaging }\end{array}$ \\
\hline $5(66 / M)$ & ERCP & Convulsion; left hemiplegia & $4: 42$ & $2(2: 0)$ & $\begin{array}{l}\text { Fully recovered and bubbles resolved } \\
\text { on } \mathrm{CT} \text { imaging }\end{array}$ \\
\hline $6(72 / M)$ & Lung biopsy & Asymptomatic & $6: 25$ & $1(1: 0)$ & $\begin{array}{l}\text { Remained asymptomatic with bubbles } \\
\text { resolved on CT imaging }\end{array}$ \\
\hline
\end{tabular}

Abbreviations: $\mathrm{CT}=$ computed tomography; ERCP = endoscopic retrograde cholangiopancreatography; HBOT = hyperbaric oxygen therapy

outcome with mean delay 8.8 hours. ${ }^{4}$ Although probability of a good outcome is highest when HBOT is administered as soon as possible, a good response can still be obtained if treatment is delayed for longer than 24 hours. ${ }^{3,5}$ There is a tendency for patients with AGE to deteriorate after their initial apparent recovery; thus, early $\mathrm{HBOT}$ is still recommended for patients with a seemingly spontaneous recovery. Although identification of gas bubbles on CT of the brain is not a prerequisite to HBOT, early treatment can also attenuate leucocyte adherence to damaged endothelium and secondary inflammation that in turn facilitate the return of blood flow. However, gas bubbles can persist for several days, and many case reports have demonstrated the benefit of HBOT after delays ranging from hours to days. Complete recovery has been reported in one patient in whom treatment was delayed for 28 hours. In 2017, another patient who was deeply comatose with AGE recovered and was able to lead a functional life after HBOT had been delayed for 6 days. ${ }^{7,8}$ In our cases, all the patients were treated within 7 hours onset of symptoms. Most fully recovered except for Patient 1 . The aetiology of neurological deterioration in Patient 1 was likely due to a combination of gas embolism, clots, and hypotension.

\section{Hyperbaric oxygen therapy treatment tables}

According to the United States Navy Diving Manual, ${ }^{9}$ USNTT6 is the standard initial compression therapy for AGE. It is a table with maximum pressure up to 2.8 atmospheres absolute (ATA) for 1 hour 15 minutes with slow depressurisation to 1.9 ATA lasting for 2.5 hours. Total treatment time is approximately
4 hours 45 minutes. There is no conclusive evidence that use of pressure higher than 2.8 ATA has any advantage. Use of pressure up to 6 ATA poses further risks to the patient and attending staff, including gas toxicity and decompression sickness. Typically, one to three hyperbaric treatments are required to treat AGE; the clinical condition should be monitored until there is no further stepwise improvement. There are reports that up to 10 treatments have been required to reach a stable condition. ${ }^{10,11}$

The USNTT5, which is a shorter treatment used to treat mild decompression sickness, may be used together with USNTT6 for AGE when prolonged treatment is required. This treatment table advises a maximum pressure up to 2.8 ATA for 45 minutes with slow depressurisation to 1.9 ATA for 30 minutes. Total treatment time is approximately 2 hours 15 minutes. According to the Royal Navy Diving manual, ${ }^{12}$ which is commonly used in Europe, RN62 Table is the standard to treat AGE. This treatment is similar to USNTT6 with a maximum pressure of 2.8 ATA.

\section{Conclusion}

Arterial gas embolism presents in highly variable ways with no pathognomonic signs or symptoms. It is uncommon to achieve complete consensus on the diagnosis, and it is common practice to err on the side of caution. Hyperbaric oxygen therapy should be initiated as early as possible although delayed treatment is also effective. Failure to administer treatment can result in long-term disability. Hyperbaric oxygen therapy should be considered for any suspected AGE. 


\section{Author contributions}

Concept or design: JCW Chau.

Acquisition of data: JCW Chau.

Analysis or interpretation of data: JCW Chau.

Drafting of the manuscript: All authors.

Critical revision of the manuscript for important intellectual content: All authors.

All authors had full access to the data, contributed to the study, approved the final version for publication, and take responsibility for its accuracy and integrity.

\section{Conflicts of interest}

All authors have disclosed no conflicts of interest.

\section{Funding/support}

This study received no specific grant from any funding agency in the public, commercial, or not-for-profit sectors.

\section{Ethics approval}

The patients were treated in accordance with the Declaration of Helsinki. The patients provided informed consent for the treatment/procedures, and verbal consent for publication.

\section{References}

1. United States Navy. Diagnosis and treatment of decompression sickness and arterial gas embolism. In: US Navy Diving Manual. Revision 7. Vol 5. Available from: https://www.navsea.navy.mil/Portals/103/Documents/ SUPSALV/Diving/US\%20DIVING\%20MANUAL_REV7. pdf?ver=2017-01-11-102354-393. Accessed 30 Sep 2020.

2. Grim PS, Gottlieb LJ, Boddie A, Batson E. Hyperbaric oxygen therapy. JAMA 1990;263:2216-20.

3. Blanc P, Boussuges A, Henriette K, Sainty JM, Deleflie M.
Iatrogenic cerebral air embolism: importance of an early hyperbaric oxygenation. Intensive Care Med 2002;28:55963.

4. Beevor H, Frawley G. Iatrogenic cerebral gas embolism: analysis of the presentation, management and outcomes of patients referred to The Alfred Hospital Hyperbaric Unit. Diving Hyperb Med 2016;46:15-21.

5. Massey EW, Moon RE, Shelton D, Camporesi EM. Hyperbaric oxygen therapy of iatrogenic air embolism. J Hyperb Med 1990;5:15-21.

6. Pearson RR, Goad RF. Delayed cerebral edema complicating cerebral arterial gas embolism: case histories. Undersea Biomed Res 1982;9:283-96.

7. Benson J, Adkinson C, Colier R. Hyperbaric oxygen therapy of iatrogenic cerebral arterial gas embolism. Undersea Hyperb Med 2003;30:117-26.

8. Perez MF, Ongkeko Perez JV, Serrano AR, Andal MP, Aldover MC. Delayed hyperbaric intervention in lifethreatening decompression illness. Diving Hyperb Med 2017;47:257-9

9. United States Navy. US Navy Diving Manual. Revision 7. Vol 5: Diving medicine and recompression chamber operations. 2016. Available from: https://www.navsea. navy.mil/Portals/103/Documents/SUPSALV/Diving/ US\%20DIVING\%20MANUAL_REV7.pdf?ver=2017-0111-102354-393. Accessed 30 Sep 2020.

10. Vann RD, Butler FK, Mitchell SJ, Moon RE. Decompression illness. Lancet 2011;377:153-64.

11. Undersea \& Hyperbaric Medical Society. UHMA Best Practice Guidelines: Prevention and Treatment of Decompression sickness and arterial gas embolism. Available from: https://www.uhms.org/images/DCSAGE-Committee/dcsandage_prevandmgt_uhms-fi.pdf. Accessed 30 Sep 2020.

12. Royal Navy, Ministry of Defence. Diving Manual. HM Stationery Office, London; 1972. 